\title{
PENGARUH GAYA HIDUP HEDONISME DAN POLA ASUH AUTORITATIF TERHADAP PENYIAPAN KEHIDUPAN BERKELUARGA PADA REMAJA
}

\author{
Muro'atul Qibtiyah ${ }^{1}$, Ibnu Mahmudi ${ }^{2}$, Diana Ariswanti Triningtyas ${ }^{3}$ \\ ${ }^{1}$ Fakultas Keguruan dan Ilmu Pendidikan, Universitas PGRI Madiun \\ Muroatul_qibtiyah@yahoo.co.id \\ ${ }^{2}$ Fakultas Keguruan dan Ilmu Pendidikan, Universitas PGRI Madiun \\ mahmudiibnu@gmail.com \\ ${ }^{3}$ Fakultas Keguruan dan Ilmu Pendidikan, Universitas PGRI Madiun \\ dianaariswanti@unipma.ac.id
}

\begin{abstract}
Abstrak
Kehidupan keluarga di Desa mengalami perubahan yang semakin cepat, sebagai dampak dari kemajuan di segala bidang, terutama semakin lancarnya komunikasi dan transportasi yang memudahkan mereka mengakses segala sesuatu. Orang tua perlu memonitor perilaku remaja serta memahami perkembangan remaja untuk menentukan masa depan anak. Remaja juga memerlukan banyak informasi tentang persiapan kehidupan berkeluarga untuk membangun keluarga yang sejahtera. Tujuan dalam penelitian ini adalah mengetahui Pengaruh Gaya Hidup Hedonisme dan Pola Asuh Autoritatif Terhadap Kesiapan Hidup Berkeluarga pada Remaja di Desa Pragak Kecamatan Parang Kabupaten Magetan. Penelitian ini menggunakan metode korelasional ex post facto. Populasi penelitian adalah 60 orang remaja berusia 17 sampai 21 tahun yang dilaksanakan di Desa Pragak Kecamatan Parang, Kabupaten Magetan dengan menggunakan teknik purposive sampling. Teknik pengambilan data dalam penelitian ini melalui angket dengan model Skala Likert. Teknik analisis data yang digunakan dalam penelitian ini adalah teknik Analisis Korelasi Regresi dua predictor dan Uji F. Hasil penelitian menunjukkan, ada pengaruh yang signifikan Gaya Hidup Hedonisme Terhadap Kesiapan Hidup Berkeluarga pada Remaja Desa Pragak Kecamatan Parang Kabupaten Magetan, diterima. gaya hidup seseorang tercipta adanya kebiasaan orang tua dalam mengasuh anaknya. Orang tua dengan kondisi ekonomi rendah cenderung untuk menikahkan anaknya di usia muda sehingga setelah menikah seringkali mengalami kesulitan ekonomi. Sedangkan orang tua dengan ekonomi tinggi cenderung menunda pernikahan anaknya sehingga anak akan lebih mementingkan karir dari pada pernikahan.
\end{abstract}

Kata Kunci: Gaya Hidup Hedonisme, Pola Asuh Autoritatif, Kesiapan Hidup Berkeluarga.

\footnotetext{
Abstract

Family life in the village is changing rapidly, as a result of progress in all areas, especially the smoothness of communication and transportation that makes it easier for them to access everything. Parents need to monitor adolescent behavior as well as understand the development of adolescents to determine the future of the child. Teens also need a lot of information about the preparation of family life to build a prosperous family. The purpose of this research is to know the influence of Hedonism Lifestyle and Autoritative Foster Pattern to Prepared Family Family Preparedness in Pragak Village, Parang Subdistrict, Magetan Regency. This research uses correlational ex post facto method. The study population was 60 people aged 17 to 21 years old which was conducted in Pragak Village District of Parang, Magetan Regency by using purposive
} 
sampling technique. Technique of taking data in this research through questionnaire with Likert Scale model. Data analysis technique used in this research is the technique of Correlation Analysis of two predictor Regression and Test F. The results showed, there is a significant influence Hedonism Lifestyle Against Preparedness of Family Life in Pragak Village Teens Parang District Magetan Regency, accepted. one's lifestyle created a parent's habit of parenting. Parents with low economic conditions tend to marry off their children at a young age so that after marriage often experience economic difficulties. While parents with high economic tend to delay the marriage of their children so that children will be more concerned about the career than at the wedding.

Keywords: Hedonism Lifestyle, Autoritative Care Pattern, Family Preparedness Readiness.

\section{PENDAHULUAN}

Kehidupan yang semakin modern membuat para remaja sangat antusias terhadap adanya hal-hal baru sehingga tercipta gaya hidup hedonisme sebagai bentuk ekspresi diri untuk bersaing mengejar modernitas fisik, ingin menarik perhatian dengan tampil modis dan trendi agar tidak terlihat kolot. Remaja yang mempunyai gaya hidup seperti ini dipengaruhi oleh banyak faktor, yakni faktor internal dan eksternal. Faktor internal misalnya adalah lingkungan sekolah, keluarga, dan pergaulan. Sementara faktor eksternal antara lain adalah tayangan televisi. (Takariani C. S. D., 2014: 43)

Gaya hidup menggambarkan keseluruhan diri seseorang yang berinteraksi dengan lingkungannya, gaya hidup adalah perpaduan antara kebutuhan ekspresi diri dan harapan kelompok terhadap seseorang dalam bertindak berdasarkan pada norma yang berlaku. Sementara itu gaya hidup hedonis adalah suatu pola hidup yang aktivitasnya untuk mencari kesenangan hidup, seperti lebih banyak menghabiskan waktu di luar rumah, lebih banyak bermain, senang pada keramaian kota, senang membeli barang mahal, serta selalu ingin menjadi pusat perhatian. Hedonisme menyatakan bahwa tujuan hidup adalah kebahagiaan atau mencapai kesenangan sebanyak mungkin (sebesar-besarnya) dengan jerih payah sesedikit mungkin (sekecil-kecilnya). (Munandar, 2012 dalam Takariani C. S. D. 2014: 43)

Gaya hidup hedonisme tidak hanya menjadi budaya pada remaja diperkotaan saja tetapi di daerah pinggiran seperti di Desa pun sudah mulai mengikuti gaya hidup hedonisme. Remaja Desa menganggap budaya kota itu sebagai hal yang modern yang harus diikuti. Keadaan itu menimbulkan krisis masyarakat dan keluarga. Willis, (2011:65) berpendapat bahwa minat remaja Desa untuk mengikuti perkembangan budaya kota tak dapat ditahan. Orang tua di Desa yang minim pendidikan beranggapan bahwa apa yang mengalir dari kota ke desa adalah kemajuan yang harus diikuti. Akan tetapi sebagian besar orang tua merasakan bahwa "kemajuan" tersebut merupakan penyimpangan terhadap norma agama dan adat setempat.

Sebagian besar orang tua dewasa ini merasa kurang memiliki kemampuan secara efisien dalam mengasuh anak remaja terutama 
dalam mengasuh anak remaja adalah memahami bagaimana masa depan anak dan bagaimana cara mempersiapkan anak untuk dapat berperan sebagai orang dewasa. Untuk itu dalam mengasuh anak remaja, orangtua harus mempunyai strategi pengasuhan sesuai dengan perkembangan remaja. Salah satu bentuk pengasuhan yang sudah populer adalah gaya pengasuhan autoritatif, dan ini merupakan gaya pengasuhan berupa monitor dari orang tua terhadap aktivitas remaja, keberadaannya dan teman-teman bergaulnya agar orang tua secara bijaksana dapat sedikit demi sedikit melepas kontrolnya sehingga anak dapat berdiri sendiri jika sudah dewasa. Santrock J.W (2007:15) mengartikan pola asuh otoritatif (Authoritative Parenting) mendorong remaja agar mandiri namun masih membatasi dan mengendalikan aksiaksi mereka. Orang tua dengan pengasuhan autoritatif memberikan kesempatan kepada anak-anaknya untuk berdialog secara verbal. Disamping itu orang tua juga bersikap hangat dan mengasuh. Pengasuhan orang tua yang bersifat autoritatif berkaitan dengan perilaku remaja yang kompenten secara sosial. Saat orang tua menggunakan pola asuh ini maka orang tua akan menyediakan lingkungan rumah yang penuh kasih dan suport, menerapkan ekspektasi dan standar yang tinggi dalam berperilaku, menjelaskan mengapa beberapa perilaku dapat diterima sedangkan perilaku lainnya tidak, menegakkan aturan-aturan keluarga secara konsisten, melibatkan anak dalam proses pengambilan keputusan didalam keluarga, serta secara bertahap melonggarkan batasanbatasan saat anak semakin bertanggungjawab dan mandiri. (Ormrod, 2008: 95)

Salah satu yang harus orang pahami dalam perkembangan remaja adalah kesiapan anak dalam memasuki kehidupan berkeluarga. Sebelum memasuki kehidupan berkeluarga para remaja diharapkan memiliki informasi yang tepat dan benar tentang kehidupan berkeluarga, sehingga para remaja mampu membina kehidupan berkeluarga yang sejahtera. Karena menikah di usia muda memiliki potensi lebih besar untuk gagal (cerai) karena ketidaksiapan mental dalam menghadapi dinamika rumah tangga dan tanggungjawab atas peran masing-masing.

Kesiapan hidup berkeluarga bagi remaja adalah upaya untuk menumbuh kembangkan kehidupan remaja yang tegar dalam rangka memasuki kehidupan berkeluarga melalui penyiapan remaja tentang konsep dan contoh-contoh kehidupan berkeluarga yang ideal. Tujuan penyiapan kehidupan berkeluarga bagi remaja adalah untuk memperkaya dan meningkatkan kualitas hidup individu dan keluarga. (BKKBN, 2010: 27).

Kennedi, 2005 (dalam Krisnatuti \& Oktaviani, 2010: 30) menjelaskan ada enam upaya persiapan pernikahan yang perlu dilakukan. Upaya tersebut adalah siapa dan bagaimana keadaan kedua pasangan sebelum memasuki kehidupan keluarga, kesehatan jasmani dan rohani kedua pasangan ketika memasuki kehidupan pernikahan, pemahaman kedua pasangan tentang kehidupan 
pernikahan dan berkeluarga, suasana keluarga tempat kedua pasangan dibesarkan, kondisi sosial budaya dan ekonomi keluarga, dan keyakinan hidup beragama.

Banyak remaja di Desa Pragak yang kurang memiliki pengetahuan tentang persiapan pernikahan dan persiapan untuk membangun keluarga baru. Hal ini disebabkan rendahnya pendidikan dan pengetahuan orang tua dalam mengasuh anaknya, serta didukung dengan rendahnya pendidikan remaja membuat remaja lebih mementingkan kenikmatan hidup dari pada melanjutkan pendidikan kejenjang berikutnya dengan bekerja di luar Kota maupun luar negeri agar mampu mengikuti budaya perkotaan yang lebih maju dan mampu memperbaiki ekonomi keluarga serta mampu bersaing dari segi ekonomi.

Berdasarkan hasil studi pendahuluan tersebut dapat diketahui bahwa remaja masih mempunyai kesiapan yang rendah untuk membangun kehidupan berkeluarga. Dengan demikian peneliti tertarik untuk mengkaji apakah ada Pengaruh Gaya Hidup Hedonisme dan Pola Asuh Autoritatif Terhadap Penyiapan Kehidupan Berkeluarga pada Remaja Desa Pragak Kecamatan Parang Kabupaten Magetan”.

\section{METODOLOGI PENELITIAN}

Penelitian ini merupakan jenis penelitian korelasional yang bersifat "ex post facto". Disebut ex post facto karena data dalam penelitian ini variabel-variabel bebasnya yang berupa perilaku telah terjadi atau tidak dilakukan pada saat penelitian berlangsung. Jika memungkinkan, maka peneliti dapat melacak kembali apa yang menjadi faktor penyebab terjadinya sesuatu Arifin (2012:43).

Populasi dalam penelitian ini adalah remaja Desa Pragak yang berusia 17-21 tahun, dengan jumlah populasi sebanyak 200 orang. Dari jumlah 200 orang diambil sampel 60 orang. Penempatan sampel dengan teknik purposive sampling pengambilan sampel yang berdasarkan pada pertimbangan dan atau tujuan tertentu, serta berdasarkan ciri-ciri atau sifat-sifat tertentu yang sudah diketahui sebelumnya.

Teknik pengumpulan data dengan menggunakan angket dengan model skala likert dan dokumentasi. Sedangkan untuk menganalisis data peneliti menggunakan rumus "regresi dua predictor". Rumus bangun "Analisis Regresi Linier : Dua-Prediktor" Koefisien korelasi antara kriterium $\mathrm{Y}$ dengan $\mathrm{X}_{1}$ dan $\mathrm{X}_{2}$ dapat diperoleh dari rumus:

$$
r_{y(1,2)}=\frac{a \sum x_{1} y+b \sum x_{2} y}{\sum y^{2}}
$$

Keterangan :

${ }^{T} y(1,2)^{T} y(1,2)=$ Koefisien korelasi antara $\mathrm{Y}$ dengan $\mathrm{X}^{1}$ dan $X^{2}$

$\boldsymbol{a}=$ Koefisien prediktor

$\mathrm{X}^{1}$

$b b \quad=$ Koefisien prediktor

$\mathrm{X}^{2}$ 
86 |Jurnal Ilmiah Counsellia, Volume 7 No. 2, Nopember 2017 : 82 - 92

$\sum x_{1} y \quad=$ Jumlah produk

$\operatorname{antara} \mathrm{X}^{1}$ dan $\mathrm{Y}$

$$
\begin{aligned}
\sum x_{2} y & =\text { Jumlah produk } \\
\sum y^{2} & =\underset{\text { Jutara } \mathrm{X}^{2} \text { dan } \mathrm{Y}}{\text { kriterium } \mathrm{Y}}
\end{aligned}
$$

Dari perhitungan regresi maka akan diperoleh nilai $\mathrm{F}$ garis regresi. Rumus untuk menghitung harga Freg bagan sebagai berikut :

$$
F_{r e g}=\frac{R^{2}(N-m-1)}{m\left(1-R^{2}\right)}
$$

Keterangan :

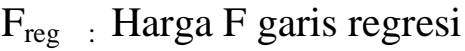

$\mathrm{N}$ : Banyaknya subjek yang terlibat

M : Banyak Prediktor
$R \quad$ : Koefisien korelasi antara kriterium dengan prediktorprediktor

\section{HASIL DAN PEMBAHASAN}

Berdasarkan

perhitungan deskripsi data analisis statistik tentang gaya hidup hedonisme dan pola asuh autoritatif terhadap penyiapan kehidupan berkeluarga pada remaja di Desa Pragak Kecamatan Parang Kabupaten Magetan. Data penelitian dapat dideskripsikan sebagai berikut:

\section{Deskripsi Data Gaya Hidup hedonisme}

Berdasarkan analisis statistik gaya hidup hedonisme yang diperoleh dari sampel sebanyak 60 remaja, dengan rentang skor antara 33-70 diperoleh lebar kelas 6, menunjukkan bahwa: Mean $=49,47$, Median $=48,38$, Modus $=46,2$ dan Standar Deviasi $=7,73$. Skor maksimal $=72$ dan skor minimal $=$ 33.

Tabel 1 Distribusi Frekuensi Data Gaya Hidup hedonisme

\begin{tabular}{ccccccl}
\hline Nilai & $\mathbf{X}$ & $\mathbf{F}$ & $\mathbf{C f}$ & $\mathbf{f X}$ & $\mathbf{X}^{\mathbf{2}}$ & $\mathbf{f}\left(\mathbf{X}^{\mathbf{2}}\right)$ \\
\hline $33-38$ & 36 & 7 & 60 & 252 & 1296 & 9072 \\
\hline $39-45$ & 42 & 9 & 53 & 378 & 1764 & 15876 \\
\hline $46-52$ & 49 & 27 & 44 & 1323 & 2401 & 64827 \\
\hline $53-59$ & 56 & 10 & 17 & 560 & 3136 & 31360 \\
\hline $60-66$ & 63 & 5 & 7 & 315 & 3969 & 19845 \\
\hline $67-72$ & 70 & 2 & 2 & 140 & 4900 & 9800 \\
\hline$\Sigma$ & & $\mathbf{6 0}$ & & $\mathbf{2 9 6 8}$ & $\mathbf{1 7 1 9 3}$ & $\mathbf{1 5 0 7 8 0}$ \\
\hline
\end{tabular}

Berdasarkan distribusi frekuensi gaya hidup hedonisme di atas maka dapat dibuat gambar 1 sebagai berikut: 


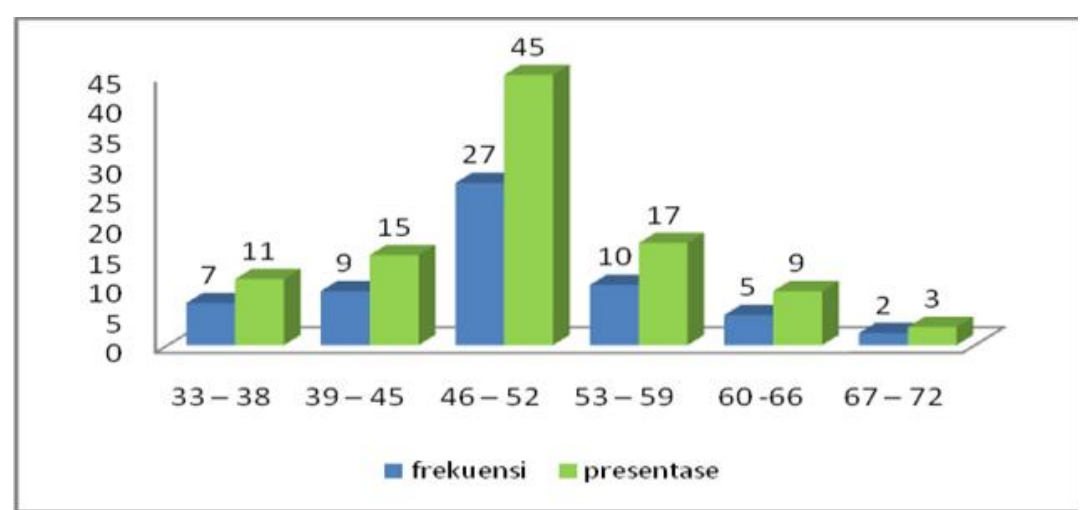

Gambar 1 Histogram Gaya hidup Hedonisme

Berdasarkan Hasil analisis data yang telah dilakukan maka pengaruh gaya hidup hedonisme terhadap penyiapan kehidupan berkeluarga menunjukan r-hitung $=0,3089$ dengan taraf signifikan $5 \%$ dan $\mathrm{N}=$ 60 setelah dikonsultasikan dengan $\mathrm{r}$ tabel $=0,254$ untuk mengetahui signifikan atau tidak signifikan, maka r-hitung $=0,3089>$ r-tabel $=$ 0,254 berarti signifikan. Dengan sumbangan efektif tingkat gaya hidup hedonisme remaja termasuk dalam kategori sedang, disebabkan dari 60 responden yang berpengaruh sebesar $7,06 \%$ terhadap kesiapan hidup berkeluarga.

Pada hasil analisis data menunjukkan jika gaya hidup hedonisme yang tidak terkendali dapat mempengaruhi bagaimana kesiapan remaja untuk berkeluarga terutama dalam pengelolaan keuangan. Sebab, remaja yang terbiasa mempunyai pengeluaran tinggi akan mengalami kesulitan dalam mengelola keuangan setelah mereka berkeluarga. Apabila pasangan suami atau istri yang memasuki kehidupan keluarga tanpa kesiapan untuk memenuhi kebutuhan-kebutuhan ekonomi keluarganya bisa berdampak padfa pasangan yang bersangkutan akan mengalami masalah dalam kehidupan berkeluarga. Idealnya setiap calon suami atau istri harus sudah menyiapkan diri agar mampu memenuhi kebutuhan primer keluarga apabila ingin membentuk keluarga baru. Dengan demikian, bagi remaja yang belum berkeluarga atau yang sudah menrencanakan untuk berkeluarga, sudah seharusnya untuk mempunyai gambaran tentang bagaimana sebaiknya keuangan keluarga itu akan dikelola, sebelum berbagai masalah akan menimpa dalam keluarga. Membangun sikap dan kebiasaan positif remaja dalam hal finansial harus menjadi perhatian utama orang tua saat ini. Dalam belajar mengelola keuangan tidak bisa dilakukan remaja dengan sendirinya. Orang tua harus mengajarkannya dengan cara memberi contoh. Oleh karena itu, orangtua harus lebih dulu memahami cara mengelola keuangan yang benar. Bukan menanamkan kebiasaan menabung atau berhemat saja, tetapi yang lebih penting adalah mengajarkan remaja cara mengambil keputusan yang tepat dalam hal keuangannya, serta sumber mendapatkan uang yang halal. Dengan demikian, remaja 
memiliki tanggung jawab dalam pengelolaan keuangannya.

\section{Deskripsi Data Pola Asuh Autoritatif}

Berdasarkan analisis statistik mengenai pola asuh autoritatif yang diperoleh dari sampel sebanyak 60 remaja, dengan rentang skor antara 77-29 diperoleh lebar kelas 6, menunjukkan bahwa: Mean $=53,33$, Median $=45,52$, Modus $=29,9$, dan Standar Deviasi $=8,36$. Skor maksimal 82 dan skor minimal 29.

Tabel 2 Distribusi Frekuensi Data Pola Asuh Autoritatif

\begin{tabular}{ccccccc}
\hline Nilai & $\mathbf{X}$ & $\mathbf{F}$ & $\mathbf{C f}$ & $\mathbf{F x}$ & $\mathbf{X}^{\mathbf{2}}$ & $\mathbf{f X}^{\mathbf{2}}$ \\
\hline $29-36$ & 32 & 1 & 1 & 32 & 1024 & 1024 \\
\hline $37-44$ & 40 & 0 & 1 & 0 & 1600 & 0 \\
\hline $45-52$ & 48 & 35 & 36 & 1681 & 2304 & 84035 \\
\hline $53-60$ & 56 & 10 & 46 & 560 & 3136 & 31360 \\
\hline $61-68$ & 64 & 11 & 57 & 704 & 4096 & 45056 \\
\hline $69-76$ & 72 & 2 & 59 & 144 & 5154 & 10368 \\
\hline $77-82$ & 80 & 1 & 60 & 80 & 6400 & 6400 \\
\hline$\sum$ & & $\mathbf{6 0}$ & & $\mathbf{3 2 0 0}$ & $\mathbf{2 3 6 9 7}$ & $\mathbf{1 7 4 8 4 8}$ \\
\hline
\end{tabular}

Berdasarkan distribusi

dapat dibuat gambar 2 sebagai frekuensi pola asuh autoritatif di atas berikut:

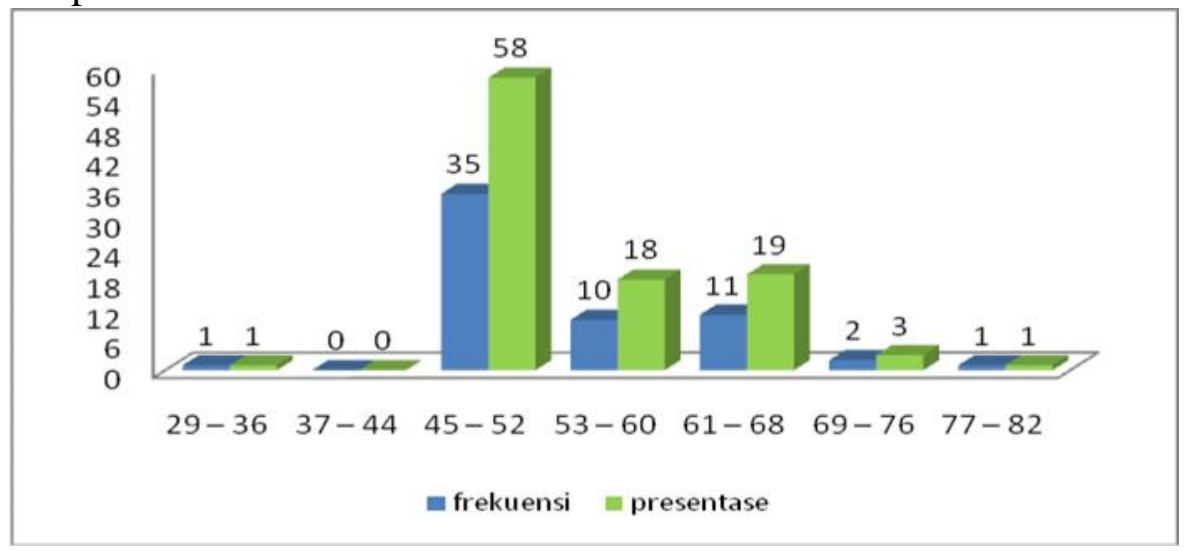

Gambar 2 Histogram Pola Asuh Autoritatif

Berdasarkan hasil analisis data pengaruh pola asuh autoritatif terhadap penyiapan kehidupan berkeluarga menunjukkan $\mathrm{r}$-hitung $=$ 0,520 dengan taraf signifikan $5 \%$ dan $\mathrm{N}=60$ setelah dikonsultasikan dengan r-tabel $=0,254$ untuk mengetahui signifikan atau tidak signifikan, maka r-hitung $=0,520>$ r-tabel $=0,235$ berarti signifikan. Dengan sumbangan efektif, tingkat pola asuh autoritatif termasuk dalam kategori tinggi, disebabkan dari 60 responden yang berpengaruh sebesar $22,84 \%$ terhadap penyiapan kehidupan berkeluarga.

Pada hasil analisis data menunjukkan jika pengasuhan orang tua semakin autoritatif maka anak semakin mempuyai persiapan yang matang untuk membangun keluarga sejahtera sehingga remaja akan lebih 
mudah menerima dan menghadapi segala konsekuensi persoalan yang timbul dalam perkawinan. Peran orang tua dalam mempersiapkan anaknya untuk menikah menjadi faktor penting yang sangat berpengaruh bagi masa depan anaknya. Setiap orang tua semestinya jeli dalam melihat perkembangan anak-anaknya. Anak yang memiliki kecenderungan untuk menikah akan memperlihatkan perilaku yang berbeda dengan anak yang belum memilikinya. Komunikasi dengan anak adalah kunci penting bagi orang tua guna memberikan pendidikan mengenai pernikahan. Pernyataan ini didukung oleh pendapat Padmomartono, (2014: 47) bahwa "anak dari gaya asuh authotitative cenderung lebih memiliki percaya diri dan merasa berkemampuan. Anak menunjukkan sikap sosial yang lebih besar, suka bereksplorasi dan menghargai orang lain".

\section{Deskripsi Data Penyiapan Kehidupan Berkeluarga}

Berdasarkan analisis statistik mengenai penyiapan kehidupan berkeluarga yang diperoleh dari sampel sebanyak 60 remaja, dengan rentang skor antara 79 - 32 diperoleh lebar kelas 6, menunjukkan bahwa; Mean $=51,01$, Median $=38,75$, Modus $=14,23$, dan Standar Deviasi $=9,66$. Skor maksimal 79 dan skor minimal 32.

Tabel 3 Distribusi Frekuensi Data Kesiapan Hidup Berkeluarga

\begin{tabular}{ccccccc}
\hline Nilai & $\mathbf{X}$ & $\mathbf{F}$ & $\mathbf{C f}$ & $\mathbf{F x}$ & $\mathbf{X}^{\mathbf{2}}$ & $\mathbf{f X}^{\mathbf{2}}$ \\
\hline $32-39$ & 35 & 3 & 3 & 105 & 1225 & 3675 \\
\hline $40-48$ & 43 & 24 & 27 & 1032 & 1849 & 44376 \\
\hline $49-56$ & 52 & 14 & 41 & 728 & 2704 & 37856 \\
\hline $57-64$ & 60 & 14 & 55 & 840 & 3600 & 50400 \\
\hline $65-72$ & 68 & 3 & 58 & 204 & 4624 & 13872 \\
\hline $73-80$ & 76 & 2 & 60 & 152 & 5776 & 11552 \\
\hline$\sum$ & & $\mathbf{6 0}$ & & $\mathbf{3 0 6 1}$ & $\mathbf{1 9 7 7 6}$ & $\mathbf{1 6 1 7 3 1}$ \\
\hline
\end{tabular}

Berdasarkan distribusi di atas dapat dibuat gambar 3 sebagai frekuensi kesiapan hidup berkeluarga berikut:

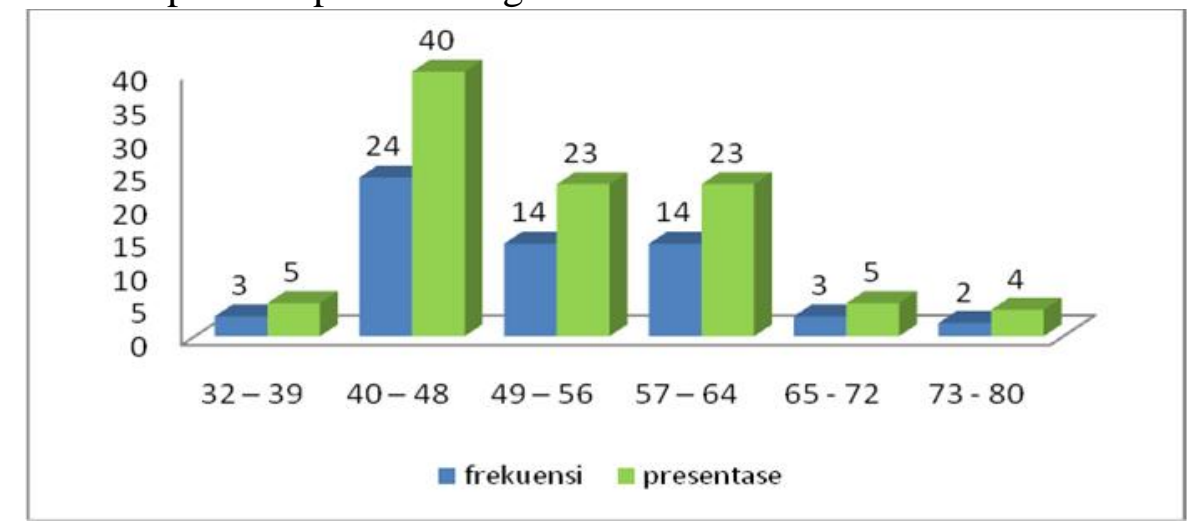

Gambar 3 Histogram Kesiapan Hidup Berkeluarga 
Berdasarkan hasil analisis data pengaruh gaya hidup hedonisme dan pola asuh autoritatif terhadap penyiapan kehidupan berkeluarga, menggunakan analisis regresi dua prediktor, diperoleh koefisien antara kriterium Y dengan prediktor X1 dan $\mathrm{X} 2$ menunjukkan r-hitung $=0,547$, maka dikonsultasikan dengan r-tabel dengan taraf signifikan 5\% maka dapat diketahui bahwa r-hitung = $0,547>$ r-tabel $=0,254$ berarti signifikan. Dari hasil perhitungan dengan menggunakan rumus $\mathrm{F}$ regresi diperoleh F-reg $=12,179$ maka dikonsultasikan dengan $\mathrm{F}$ tabel untuk jumlah $\mathrm{N}=60$ dengan taraf signifikan $5 \%$ adalah 3,15 jadi $F_{r g g} F_{r g g} \mathrm{~F}_{\text {reg }}=12,179>\mathrm{F}_{\text {tabel }}=3,12$ Dengan sumbangan efektif keseluruhan variabel dari 60 responden sebesar $29,9 \%$ dikatakan kategori tinggi. Jadi F-reg lebih besar dibandingkan dengan f-tabel, maka $\mathrm{H}_{a}$ diterima dan $\mathrm{H}_{0}$ ditolak. Dengan demikian ada pengaruh yang signifikan dari gaya hidup hedonisme dan pola asuh autoritatif terhadap kesiapan hidup berkeluarga. Hasil penelitian ini menunjukkan bahwa gaya hidup seseorang tercipta adanya kebiasaan orang tua dalam mengasuh anaknya. Orang tua dengan kondisi ekonomi rendah cenderung untuk menikahkan anaknya di usia muda sehingga setelah menikah seringkali mengalami kesulitan ekonomi. Sedangkan orang tua dengan ekonomi tinggi cenderung menunda pernikahan anaknya sehingga anak akan lebih mementingkan karir dari pada pernikahan.

\section{SIMPULAN}

Berdasarkan analisis data penelitian yang telah dilaksanakan diperoleh beberapa simpulan sebagai berikut:

1. Ada pengaruh gaya hidup hedonisme terhadap kesiapan hidup berkeluarga pada remaja di Desa Pragak Kecamatan Parang Kabupaten Magetan.

2. Ada pengaruh pola asuh autoritatif terhadap kedisiplinan belajar kesiapan hidup berkeluarga pada remaja di Desa Pragak Kecamatan Parang Kabupaten Magetan.

3. Ada ada pengaruh gaya hidup hedonisme dan pola asuh autoritatif terhadap kesiapan hidup berkeluarga pada remaja di Desa Pragak Kecamatan Parang Kabupaten Magetan.

\section{DAFTAR PUSTAKA}

Andi Mappiare. Tanpa tahun. Psikologi Orang Dewasa. Surabaya: Usaha Nasional.

Anisatriningtyas \& Astuti. (2011). Pernikahan Di Kalangan Mahasiswa S-1. Proyeksi. Vol. 6 No (2).

Arikunto, Suharsimi. (2013). Prosedur Penelitian Suatu Pendekatan Praktik. Jakarta: Rineka Cipta.

Arifin, Zainal. (2012). Penelitian Pendidikan, Metode dan Paradigma Baru. Bandung: Remaja Rosdakarya.

Bahri, Syaiful. (2004). Pola Komunikasi Orang Tua dan Anak dalam Keluarga. Jakarta: Rineka Cipta. 
BKKBN. (2010). Penyiapan Kehidupan Berkeluarga Bagi Remaja. Jakarta: Direktorat Remaja dan Perlindungan Hakhak Reproduksi.

Dariyo, A. (2004). Psikologi Perkembangan Dewasa Muda. Jakarta: Grasindo.

Darmadi, Hamid. (2013). Dimensidimensi Metode Penelitian Pendidikan dan Sosial, Konsep Dasar dan Implementasi. Bandung: Alfabeta

Dian W. \& Sri F.M. (2012). Hubungan Interpersonal. Jakarta: Salemba Humanika.

Falsafy, Dina. (2013). Pengembangan Paket Persiapan Hidup Berkeluarga untuk Siswa Madrasah Aliyah (MA). Jurnal Bimbingan dan Konseling teori \& praktik. Vol. 29 No.1. Madiun: IKIP PGRI Madiun.

Helmawati. (2014). Pendidikan Keluarga Teoritis dan Praktis. Bandung: Remaja Rosdakarya.

Itryah.(2010). Hubungan Antara Kelompok Teman Sebaya Dengan Gaya Hidup Hedonis Pada Mahasiswa Fakultas Hukum Sore Angkatan Tahun 2009 Dan 2010 Universitas Sriwijaya Palembang. Jurnal Ilmiah PSYCHE. Vol.9 No.1.

Iskandar. (2012). Dakwah Dan Individualisme, Materialisme Dan Hedonisme. Jurnal Dakwah Tabligh. Vol. 13, No. 1.

Kartono Kartini. (1992). Psikologi Wanita (jilid 1) Mengenal Gadis Remaja \& Wanita Dewasa. Bandung: Mandar Maju.
KBBI (Kamus Besar Bahasa Indonesia). (2005). Semarang: Widya Karya.

Krisnatuti \& Oktaviani O. (2010). Persepsi Dan Kesiapan Menikah Pada Mahasiswa. Jur. Ilm. Kel. \& Kons. Vol. 4, No. 1.

Muchson \& Samsuri. (2013). Dasardasar Pendidikan Moral. Yogyakarta: Ombak dua.

Nani Sri Handayani \& Zahrotul 'Uyun. (2004). Pengaruh Tingkat Religiusitas Terhadap Kesiapan Menghadapi Perkawinan Mahasantri Pondok Muhammadiyah Hajjah Nuriyah Shabran Surakarta. Vol. 2, No. 2. Jounal Tajdida.

Noor, Juliansyah. (2011). Metode Penelitian Skripsi, Tesis, Desertasi dan Karya Ilmiah. Jakarta: Kencana predana media group.

Ormrod. (2008). Psikologi Pendidikan. Jakarta: Erlangga.

Papalia, Olds, Feldman. (2009). Human Development Perkembangan Manusia. Jakarta: Salemba Humanika.

Padmomartono S. (2014). Konseling Remaja. Yogyakarta: Ombak.

Riyadi, Agus. (2013). Bimbingan Konseling Perkawinan, Dakwah dalam Membentuk Keluarga Sakinah. Yogyakarta: Ombak

Salam , B. (1997). Etika Sosial. Jakarta: Rineka Cipta

Santrock. J.W. (2007). Remaja. Jakarta: Erlangga.

Sugiyono. (2015). Metode Penelitian \& Pengembangan Reseach And Development. Bandung: Alfabeta. 
92 |Jurnal Ilmiah Counsellia, Volume 7 No. 2, Nopember 2017 : 82 - 92

Takariani C.S.D. (2013). Pengaruh Sinetron Remaja Di Televisi Swasta Terhadap Sikap Mengenai Gaya Hidup Hedonis. Jurnal Penelitian Komunikasi. Vol. 16 No. 1.

Trimartati. N. (2014). Studi Kasus

Tentang Gaya Hidup

Hedonisme Mahasiswa

Bimbingan dan Konseling

Universitas Ahmad Dahlan.

Psikopedagogia. Vol. 3, No.1.

Walgito, Bimo.(2010). Bimbingan
Konseling
Perkawinan.

Yogyakarta: Andi Offset.

Willis, Sofyan S. (2011). Konseling Keluarga (Family Counseling). Bandung: Alfabeta.

Winanti, dkk. (2006). Perbedaan Konsep Diri Antara Remaja Akhir Yang Mempersepsi Pola Asuh Orang Tua Authoritarian, Permissive Dan Authoritative. Jurnal Psikologi (online). Vol. 4 No. 2.

Zulkifli A.R. (2016). Gaya Hidup Hedonisme Di Kalangan Mahasiswa Penerima Beasiswa Kaltim Cemerlang 2014 Di Fakultas Ilmu Sosial Dan Ilmu Politik Universitas Mulawarman. eJournal Sosiatri-Sosiologi. Volume 4, Nomor 1 